\title{
DÍA SÁNCHEZ DE QUESADA. UN CORREGIDOR AL SERVICIO DE LOS REYES CATÓLICOS*
}

\author{
DÍA SÁNCHEZ DE QUESADA. \\ A CORREGIDOR IN THE SERVICE OF THE CATHOLIC KINGS
}

\author{
MARÍA ANTONIA CARMONA RUIZ \\ Universidad de Sevilla \\ http://orcid.org/0000-0003-1085-693X
}

\begin{abstract}
Resumen: En este artículo se analiza la biografía de uno de los corregidores que tuvieron una vida más dilatada al servicio de los Reyes Católicos, y con una actuación más polémica: Día Sánchez de Quesada, miembro de uno de los linajes más influyentes del reino de Jaén, que contaba en su patrimonio con el señorío de las localidades jienenses de Garcíez y Santo Tomé, y que se asentaron en la cercana ciudad de Baeza, formando parte de su gobierno como regidores. Conocemos su labor al servicio de la corona a partir de 1485, año que fue como pesquisidor a la villa de Alcaraz. Un año después era nombrado corregidor de Segovia, continuando su labor en Cuatro Villas y merindad de la Trasmiera, Madrid, Alcaraz, Trujillo y Zamora, hasta 1507, año de su fallecimiento.
\end{abstract}

Palabras clave: corregidor; Reyes Católicos; Alcaraz; Madrid; Trujillo; Zamora; Cuatro Villas; Trasmiera.

\begin{abstract}
This paper discusses the biography of one of the corregidores who spent most time in the service of the Catholic Kings, noted for his very controversial actions: Día Sánchez de Quesada. He was a member of one of the most influential families in the kingdom of Jaén, whose patrimony included the lordship of the localities of Garcíez and Santo Tomé, in Jaén, and who established themselves in the nearby town of Baeza, taking part in its government as aldermen. We know about his work in the service of the Crown after 1485, the year he went as an investigator to the town of Alcaraz. A year later he was appointed corregidor of Segovia, continuing his work in Cuatro Villas and the Merindad of Trasmiera, Madrid, Alcaraz, Trujillo and Zamora, until his death in 1507.
\end{abstract}

Keywords: corregidor, Catholic Kings, Alcaraz, Madrid, Trujillo, Zamora, Cuatro Villas, Trasmiera.

\footnotetext{
*Este trabajo forma parte del proyecto de investigación financiado por el Ministerio de Economía y Competitividad y que lleva por título "Poder, fiscalidad y sociedades fronterizas en la Corona de Castilla al sur del Tajo (siglos XIV-XVI)" (referencia HAR2014-52469-C3-1-P).
} 


\section{SUMARIO}

1. Introducción.- 2. Día Sánchez de Quesada, señor de Garcíez y Santo Tomé.- 3. La actuación personal del corregidor Día Sánchez de Quesada.- 4. Los colaboradores de Día Sánchez de Quesada.- 5. La presencia del corregidor en los concejos (absentismo y salario).- 6. Denuncias presentadas contra la gestión de Día Sánchez de Quesada. Los juicios de residencia.- 7. Conclusiones.

\section{INTRODUCCIÓN}

Uno de los principales mecanismos que la corona castellana utilizó para controlar y, en cierta manera, dirigir la vida política de las ciudades fue la implantación del oficio del corregimiento, que dependía directamente del Consejo Real y que se colocó a la cabeza del gobierno municipal. Éste existía desde el reinado de Alfonso XI, pero fue evolucionando a lo largo de los siglos XIV y XV a la par que la intervención de la monarquía en los distintos aspectos de la vida municipal se incrementaba, consiguiendo su grado de madurez durante el reinado de los Reyes Católicos, momento en que se regularizó la práctica de enviarlos a los concejos castellanos. Las atribuciones de los corregidores eran muy diversas y se referían a numerosas cuestiones administrativas, judiciales, políticas y militares, convirtiéndose en el representante por antonomasia de la autoridad y del poder real en la esfera local, lo que le revistió de categoría superior a la de cualquier otro funcionario del concejo. El desempeño de este oficio llevó consigo adscrito el de otras importantes funciones, lo cual propició que sus titulares concentrasen en sus manos elevadas cuotas de poder en el ámbito local y regional, de ahí que la corona cuidara especialmente su nombramiento, procurando que fueran personas dignas y prudentes, sin que no siempre lo consiguieran.

Aunque la bibliografía relacionada con esta figura es bastante exten$\mathrm{sa}^{2}$, lo que nos permite conocer la implantación de este oficio en los municipios castellanos, su desarrollo, sus competencias y sus relaciones con algunas de las ciudades en que gobernaron, sin embargo sabemos aún muy poco de la

\footnotetext{
${ }^{1}$ Abreviaturas utilizadas: AGS = Archivo General de Simancas; ARChGr = Archivo de la Real Chancillería de Granada; RAH = Real Academia de la Historia; RGS = Registro General del Sello; SNAHN = Sección Nobleza del Archivo Histórico Nacional.

${ }^{2}$ De entre la abundantísima bibliografía existente, destacamos González Alonso 1978, dedicado al estudio del corregimiento en general, desde sus orígenes hasta el fin del Antiguo Régimen. Sobre el origen y desarrollo de la institución en la época bajomedieval véase Bermúdez 1974, Mitre 1969, Bonachía 1998-1999, Guerrero 1994-1995. Los principales trabajos sobre el corregimiento durante el periodo de los Reyes Católicos son los de Lunenfeld 1989, Diago 2004 y González Alonso, 1995, 2000 y 2001.
} 
labor completa de cada uno de los personajes que tuvieron este cometido. Así, conocemos la actuación concreta de algunos en determinadas localidades, pero apenas se ha estudiado la biografía o la carrera íntegra de estos delegados de la corona, con cuyo análisis podríamos tener una mejor comprensión de su proceder en los concejos a los que fueron destinados. Por ello, el presente trabajo pretende profundizar en la vida y labor especifica de un corregidor concreto: Día Sánchez de Quesada, quien pertenecía a un linaje influyente en el concejo de Baeza y que en su patrimonio contaba con el señorío de las localidades de Garcíez y Santo Tomé. Destacó especialmente por su dilatada carrera como corregidor al servicio de los Reyes Católicos y su polémica actuación en algunos de los concejos en los que intervino en su cargo, lo que llevó a Marvin Lunenfeld, a decir de él que

la pugnacidad que había alrededor de Sánchez de Quesada le convirtió en un buen servidor de la Corona, apto para aceptar tareas peligrosas, pero que siempre le dejaban en medio de la polémica. Resulta sencillo violar el límite entre la agresividad y la corrupción, y éste lo cruzó a menudo. No le faltaba razón a un corregidor colega suyo al definirlo como "odioso"3.

\section{Día SÁNCHEZ DE QueSADA, SEÑOR DE GARCÍEZ y SANTO TOMÉ}

Como ya hemos indicado, el corregidor Día Sánchez de Quesada pertenecía a uno de los linajes más influyentes del reino de Jaén, que contaba en su patrimonio con el señorío de las localidades jienenses de Garcíez y Santo Tomé, y que se asentaron en la cercana ciudad de Baeza, formando parte de su gobierno como regidores. Desde su origen, este linaje se había destacado también por su leal servicio a la corona, y así, además de su continua actividad en la frontera de Granada, algunos miembros de esta familia estuvieron ligados al servicio de la monarquía en la corte o en la administración central. De hecho, el conformador del linaje, Día Sánchez de Quesada I estuvo estrechamente vinculado al rey Pedro I, consiguiendo posteriormente el perdón de Enrique II. Su hijo Pedro Díaz de Quesada I debió de entrar también desde muy joven en la corte al servicio de Pedro I, y al parecer fue paje real. Al igual que su padre, tuvo que verse afectado por el cambio de dinastía, aunque pronto sobresalió al servicio de los Trastámara, a los que tanto él como sus descendientes sirvieron

${ }^{3}$ Lunenfeld 1989, p. 112. Quien calificó a Día Sánchez de Quesada de odioso fue Diego de Mendoza, quien pidió que no fuera Día Sánchez de Quesada el que le tomase la residencia como corregidor de Salamanca alegando que le es "odioso e sospechoso e juró que la dicha sospecha non la ponía maliciosamente”. 1494, octubre, 15. Madrid. AGS, RGS, 149410, 459. 
en embajadas y acciones diplomáticas ${ }^{4}$. El propio Día Sánchez de Quesada III antes de ser corregidor, fue contino de la casa real y en 1485 fue enviado por los Reyes Católicos como pesquisidor especial para que reprimiera la revuelta que protagonizaban sus vecinos contra el corregidor Fernando de Talavera ${ }^{5}$.

Como otros linajes andaluces, destacaron igualmente por su función militar en la frontera con el reino de Granada, y de hecho, por la especial significación de Pedro Díaz de Quesada I en la defensa de Baeza en 1407, el rey le concedió, entre otras cosas, 15 lanzas en tierras del rey, que heredarían sus descendientes ${ }^{6}$.

En relación a la actividad de Día Sánchez de Quesada III, tanto respecto a sus propiedades como al gobierno de la ciudad de Baeza, tenemos pocas noticias. De hecho, y aunque mantuvo su cargo como regidor, su servicio a la corona hasta su muerte, sobrevenida en 1507, apenas le permitió la intervención en los asuntos concejiles de Baeza y la administración de sus señoríos. Fue nombrado regidor en 1476, ante la renuncia de su padre, Pedro Díaz de Quesada II, a su favor ${ }^{7}$, aunque la reina hizo merced a este último de retener este oficio durante su vida, siempre que no se consideraran dos oficios ${ }^{8}$, por lo que es más que probable que fuera su padre el que continuara ejerciendo el cargo y la cesión al hijo fuera tan sólo una forma de garantizar su transmisión familiar, algo, por otro lado, bastante habitual ${ }^{9}$.

Aunque intervino poco en la política local baezana, sin embargo, todavía en vida de su padre tuvo cierto protagonismo en la lucha de bandos que se produjo en la ciudad a consecuencia de la guerra civil castellana, y así, fue uno de los caballeros que en 1466 defendieron el alcázar de Baeza -que Pedro Girón había ocupado en 1464-, ante el intento de don Miguel Lucas de conquistarlo ${ }^{10}$. Por otro lado y después de numerosas discordias con Juan de Benavides, señor de Jabalquinto, en 1478 asentaron un pacto de amistad ${ }^{11}$. Imaginamos que tuvo que ser un enfrentamiento de carácter personal, puesto que los Quesada estaban integrados dentro del bando de los Benavides. De

\footnotetext{
${ }^{4}$ La evolución de este linaje en época medieval está analizada en los trabajos de Carmona Ruiz 2015 y 2017a.

${ }^{5}$ Pretel 1978, p. 175.

${ }^{6}$ SNAHN, Baena, C. 82, D. 18.

${ }^{7}$ 1476, mayo, 24. Valladolid. La reina Isabel autoriza a Pedro Díaz de Quesada a renunciar al oficio de regidor en favor de su hijo Día Sánchez de Quesada. AGS, RGS, 147605, 283.

8 1476, mayo 24. Valladolid. Archivo y Biblioteca de Francisco Zabálburu, Altamira, 222, D.6.

${ }^{9}$ Así, Parejo 1988, p. 200 señala que el 89,7\% de los regidores de los que tiene constancia documental entre 1401 y 1520 (68), ocuparon su cargo por herencia paterna.

${ }^{10}$ Cózar 2006, pp. 274-275.

${ }^{11} 1478$, agosto, 28, SNAHN, Osuna, lib. 108, doc. 39.
} 
hecho, casi dos meses antes de esta concordia, se establecieron las capitulaciones matrimoniales entre el primogénito de Día Sánchez de Quesada, Pedro Díaz, e Isabel de Benavides, hija del señor de Jabalquinto ${ }^{12}$.

Su mujer, doña Leonor de Acuña, se vio también implicada en estos conflictos, y así, cuando don Pedro Girón cercó al obispo en el castillo de Begíjar, éste entregó a doña Leonor, que era su parienta, como rehén, permaneciendo como prisionera durante más de cuatro años "padeciendo muchos trabajos e aflicciones e grandes enfermedades" ${ }^{\prime 3}$. Por ello, y como indemnización de los perjuicios que le había ocasionado, en 1469 don Alonso Vázquez de Acuña le entregó una importante dote para el matrimonio que ya había contraído con Día Sánchez de Quesada III ${ }^{14}$.

A la muerte de su padre, Pedro Díaz de Quesada II, en 1480 se hacía cargo del mayorazgo, compuesto de las villas de Garcíez y Santo Tomé, la dehesa de la Torre de don Ibáñez y las casas de Baeza ${ }^{15}$. Este patrimonio se incrementó en 1486, cuando Día Sánchez de Quesada compró Nínchez y Chozas, heredamientos contiguos al señorío de Garcíez, empleando para ello buena parte de la dote de su mujer, por lo que tras su fallecimiento ella dispuso de estas tierras libremente ${ }^{16}$.

Su intensa actividad al servicio de los Reyes Católicos le impidió ocuparse directamente de la administración de sus propiedades. Por ello era su primogénito, Pedro Díaz de Quesada III, el que debía de estar al frente del señorío. Pero debido a sus continuas ausencias, realmente fue doña Leonor de Acuña la que se encargó de su gobierno, responsabilidad que mantuvo tras el prematuro fallecimiento de su hijo, durante la minoría de edad de su nieto Día Sánchez de Quesada ${ }^{17}$. El continuado abandono de Pedro Díaz de sus obligaciones posiblemente se debió a su conflictivo carácter y a los problemas que

${ }^{12}$ 1478, julio, 3. Baeza. SNAHN, Osuna, lib. 108, doc. 38 (inventario del archivo de Jabalquinto, publicado por Porras, 1993).

${ }^{13}$ SNAHN, Baena, C. 68, D. 5.

${ }^{14}$ Consistía en una serie de propiedades en los términos de Andújar y de Baeza. Así, en término de Andújar recibió las aceñas de Villalva y unas casas en la ciudad de Andújar, denominadas "las casas de Palacio", en la collación de Santa Marina. En término de Baeza obtuvo la heredad del campillo de la Higueruela y Casalva. 1469, noviembre, 11. Begíjar. SNAHN, Baena, C. 68 , D. 5.

${ }^{15}$ 1480, diciembre 23, Baeza. SNAHN, Baena, C. 339.

16 1486, noviembre 27, [Córdoba]. SNAHN, Baena, C. 137, D. 175. Pagó 900.000 mrs. en puja frente a Día Sánchez de Carvajal. Para poder hacer frente a la compra de Nínchez y Chozas, Día Sánchez de Quesada vendió en 1487 unas casas palacio en Andújar, en la collación de Santa Marina y las aceñas de Villalva, situadas en término de Andújar en el río del Guadalquivir a favor del comendador Gutierre de Cárdenas, por 1.040.000 mrs. libres de alcabalas. 1487, noviembre 21, Baeza. SNAHN, Baena, CP. 2, D. 9 . Un análisis más exhaustivo de esta compra en Carmona Ruiz 2009 y 2017a.

${ }^{17}$ Cfr. Carmona Ruiz 2017b. 
éste le acarreó, provocando abundantes pleitos a los que sus padres tuvieron que hacer frente económicamente ${ }^{18}$. Pero lo que posiblemente le marcó su existencia fue el asesinato a puñaladas del canónigo de Jaén Francisco Reolid en 1499 y su posible condena al destierro, terminando sus días en Granada ${ }^{19}$. El propio Día Sánchez de Quesada tuvo también un fuerte temperamento que le llevó a protagonizar acciones muy violentas a lo largo de su vida. Parte de ellas se produjeron durante el desempeño de su cargo como corregidor, pero también en Baeza fue el protagonista de algún altercado. Así, en 1505 planeó matar al juez de términos Lope de Celaya, posiblemente debido al pleito que mantenía con la ciudad por la propiedad de la dehesa de la Torre Don Ibáñez, ya que el magistrado había fallado en su contra ${ }^{20}$. A consecuencia de ello, Día Sánchez mandó a un criado suyo a la posada a que lo asesinara, pero éste se equivocó acuchillando por error a un escribano ${ }^{21}$.

\section{LA ACTUACIÓN PERSONAL DEL CORREGIDOR DÍA SÁNCHEZ DE QUESADA}

Como ya hemos visto, siguiendo la tradición familiar, Día Sánchez de Quesada tuvo cierta vinculación con la corte real, y por ello en numerosos documentos los Reyes Católicos destacan que era contino de la casa real. En esta posición tuvo que mostrar cualidades suficientes para que en 1485 fuera enviado a Alcaraz como pesquisidor. Su actividad estaba encaminada a investigar al corregidor Fernando de Talavera y a reprimir la revuelta que protagonizaban sus vecinos en su contra. No era la primera vez que esta villa había protagonizado desórdenes, y de hecho durante el siglo XV los levantamientos ciudadanos se habían sucedido, con mayor éxito tras la muerte de Enrique $\mathrm{IV}^{22}$. A partir de entonces se realizaron continuos ataques contra los corregidores, hasta que finalmente éstos se transformaron en una revuelta contra Fernando de Talavera, tras intentar éste prender por orden real a un vecino, el bachiller Ruy Díaz. Posteriormente a estos incidentes Día Sánchez de Quesada irrumpió violentamente en la ciudad, combatiendo la revuelta enérgica-

${ }^{18}$ Era conocido como el del reto porque retó a los Molina de Úbeda. Asçendençia de los señores de la cassa de Garçiez.... RAH, Colección Salazar, 09-00201 (B-92), f. 189r.

${ }^{19}$ Para mayor información véase Carmona Ruiz 2015.

${ }^{20}$ En 1504 el bachiller Lope de Celaya dio sentencia a favor de Baeza, pero Día Sánchez recurrió a Chancillería, consiguiendo que ésta le restituyera las tierras. La sentencia definitiva de este proceso se dio el 18 de febrero de 1505, y el 20 de febrero doña Juana solicitaba información por el intento de asesinato del juez. Sobre el pleito que los Quesada mantuvieron con Baeza por la propiedad de la dehesa de la Torre de Don Ibáñez, véase Carmona Ruiz 2012.

${ }^{21} 1505$, febrero, 20, Toro. AGS, RGS, 150502,423.

${ }^{22}$ Alcaraz protagonizó numerosos revueltas contra la autoridad central a lo largo del siglo XV, que han sido minuciosamente estudiadas. $C f$. Pretel 1978, 1979. Mackay 1985. 
mente y, junto al corregidor, realizó un duro programa de prisiones, multas, destierro, derribo de casas y confiscación de bienes ${ }^{23}$.

Posiblemente debido a la efectividad que mostró en su actuación, poco después, en 1486, fue nombrado corregidor de Segovia, iniciando de este modo una dilatada carrera que se prolongó hasta el momento de su fallecimiento, en 1507. Ejerció como corregidor en numerosos concejos en momentos de notable conflictividad. Debido a la eficacia que mostró con sus drásticas actuaciones y a la contundencia de sus resoluciones, la corona recurrió a él para obtener rápidos resultados. Estaba encuadrado dentro del tipo de corregidores que González Alonso denomina "de capa y espada", es decir, miembros de la nobleza ligados al ejercicio de armas, que habitualmente estaban destinados a lugares que se caracterizaban por su importancia estratégica o por la virulencia de las tensiones locales, frente a los corregidores letrados, con estudios universitarios más o menos completos, en los que era más intensa su faceta jurisdiccional ${ }^{24}$. Su connotación militar se refleja claramente en su intervención en la guerra granadina, y así, siendo corregidor de Alcaraz (14901492) participó en el cerco de Granada como capitán de esta ciudad ${ }^{25}$.

Después de actuar como pesquisidor en Alcaraz en 1485, Día Sánchez de Quesada realizó entre 1486 y 1507 una intensa labor como corregidor en diversas localidades, donde en ocasiones se le prorrogó el cargo, repitiendo también en algunas. Así, ejerció en Segovia en tres ocasiones (entre 1486-1488, 1492-1494 y 1500-1502), en las Cuatro Villas y merindad de la Trasmiera (1488-1490), Madrid (unos meses en 1490), Alcaraz (1490-1492), Salamanca (1494-1495), Trujillo (1498-1499) y Zamora, donde permaneció entre 1505 y $1507^{26}$, año en que falleció. Es decir, desarrolló esta labor de manera casi continuada desde 1486 y 1507 , con tan sólo dos intervalos de tiempo en que no parece que ejerciera este cargo (1495-1498 y 1503-1505). Puntualmente también se le encomendaron algunas pesquisas sobre algunos lugares mientras intervenía como corregidor en otros concejos, actuando como juez pesquisidor en Salamanca, en 1490, mientras ejercía como corregidor en Alcaraz, y en León en 1492, cuando era corregidor de Segovia.

Pero además de intervenir duramente en los conflictos existentes en los concejos a los que fue destinado, las funciones de Día Sánchez de Que-

${ }^{23}$ Entre los implicados había personas de todos los estamentos. Pretel 1978, pp. 175-176. Los indultos a los condenados tras el pago de las multas se realizaron el 8 de diciembre de 1485 . AGS, RGS, 148512, 90; 148512, 93; 148512, 100; 148512, 140.

${ }^{24}$ González Alonso 1978, p. 83.

${ }^{25}$ 1493, noviembre 27, Zaragoza. AGS, RGS, 149311,44.

${ }^{26}$ En AGS, RGS se conserva gran cantidad de documentación relacionada con su actividad en los diferentes concejos. 
sada como corregidor eran mucho más amplias. Según el régimen municipal elaborado por los Reyes Católicos, el corregidor se hallaba a la cabeza del gobierno municipal, por lo que presidía el cabildo municipal y ostentaba una autoridad superior a la de cualquiera de sus miembros. Tenía gran cantidad de atribuciones, destacando especialmente su capacidad judicial, la de nombrar alcaldes y alguaciles, hacer cumplir los mandatos y sentencias regios, aprestar gente armada para las huestes regias, defender las ciudades de las pretensiones señorializadoras de su entorno, visitar los términos de las villas para comprobar su integridad, ser los garantes de la paz entre los vecinos, dirimir casos de apropiación del espacio público o de la jurisdicción concejil, preocuparse del saneamiento de la hacienda municipal y la puesta al día de la contabilidad concejil, y tenían autoridad para nombrar a sus lugartenientes. Por ello, el corregidor gozaba de una gran notabilidad en todas las actividades relacionadas con la corona que tenían lugar en la ciudad, tales como celebraciones y juramentos regios.

Conservamos abundante información de su actuación judicial en los diferentes concejos en los que estuvo destinado, donde, como era habitual, sostuvo pleitos de una temática muy variada, destacando asuntos como los problemas de usurpación de términos o aprovechamiento de los propios de los concejos. También hay casos contra los concejos por abuso en la carga impositiva o por problemas en la composición de los concejos. Pero los pleitos más abundantes inciden en procesos de carácter privado, como son los problemas por el cobro de herencias o deudas, o disensiones y enfrentamientos entre vecinos, debiendo de prestar especial atención a los asuntos relacionados con la decencia y moralidad.

En muchas ocasiones fueron los miembros del Común quienes aprovecharon la llegada del corregidor para reclamarle la investigación de agresiones y muertes pasadas, algo que se puede ver por ejemplo en el caso de Las Cuatro villas, donde a consecuencia de la investigación que el corregidor había iniciado por estas solicitudes en 1489, los miembros de la oligarquía habían pedido a los Reyes Católicos que prohibiesen al corregidor Díaz Sánchez de Quesada que indagara las muertes acaecidas durante una jornada de elección de oficiales ${ }^{27}$.

Como ya hemos indicado, fue destinado como corregidor a varios concejos en momentos especialmente conflictivos, caracterizándose por actuar de forma bastante contundente. Ya hemos señalado su intervención en Alcaraz que, como hemos indicado, a lo largo del siglo XV había protagoni-

${ }^{27}$ 1489, febrero, s.d., AGS, RGS, 148902, 246.1489, febrero, 14, Medina del Campo. AGS, RGS, 148902, 308. Martín 2014, pp. 345-371. 
zado numerosas revueltas contra la autoridad central. Algo similar ocurría en las Cuatro Villas, donde distintos linajes cohesionados en torno a los bandos se repartieron el poder, pero cuando no llegaban a un acuerdo las diferencias se dirimían con el enfrentamiento violento de los bandos. El intervencionismo regio por medio de los corregidores enturbió aún más la situación, de tal manera que a partir de 1480 los conflictos banderizos se multiplicaron hasta hacer insostenible la convivencia pacífica de los vecinos ${ }^{28}$.

Fue también el encargado de atajar los alborotos que se produjeron en Salamanca en 1490, donde fue destinado como juez pesquisidor mientras era corregidor de Alcaraz, a consecuencia de una disputa entre Catalina Guzmán, viuda de Juan de Castilla Portocarrero, y Alonso Portocarrero, por una heredad, que llevó a este último a presentarse con un contingente de tropas y vecinos en dicha propiedad ${ }^{29}$. Además en 1492, mientras era corregidor de Segovia, se ocupó de la investigación de las torres y casas fuertes que se habían levantado ilegalmente en término de León y su comarca y en las que se acogían a malhechores y delincuentes ${ }^{30}$. A consecuencia de ello, se ordenó la destrucción de una casa fuerte realizada por Suero de Quiñones ${ }^{31}$. También se encargó de castigar al corregidor de León, Juan de Portugal, quien tras el edicto de expulsión de los judíos, e ignorando la orden dada en un principio de que éstos podrían disponer libremente de sus bienes ${ }^{32}$, les cobró 30.000 maravedís para ampararles y les confiscó los bienes sin pretexto alguno ${ }^{33}$. Asimismo, durante esta estancia se produjo la muerte del alguacil de León, por lo que además de confiscar los bienes de un vecino, expulsó de la ciudad a varios clérigos y beneficiados, acusados de ser culpables del homicidio ${ }^{34}$.

${ }^{28}$ Solórzano 2005, p. 345.

${ }^{29}$ 1490, septiembre 17, Córdoba. AGS, RGS, 1490009,308. 1490, septiembre 19, Córdoba. AGS, RGS, 149009,49 .

${ }^{30}$ Comisión para hacer pesquisa en 1492, marzo, 30, Santa Fe. AGS, RGS, 149203, 136 Poder para prender a los malhechores localizados en las torres en 1492, Septiembre, 13, Zaragoza. 149209, 142.

${ }^{31}$ 1492, septiembre 21, Zaragoza. AGS, RGS, 149209,273.

${ }^{32}$ Es lo que se manifiesta en una carta real realizada en Santa Fe el 14 de mayo de 1492 e incluida en una orden enviada a Amusco el 5 de junio, publicado en Suárez 1964, doc. 197, pp. 428-429.

${ }_{33}$ 1492, junio, 26, Valladolid. AGS, RGS, 149206,289.

${ }^{34}$ 1492, agosto, s.d., Zaragoza. AGS, RGS, 149208, 232. Se ordena a don Juan de Portugal, corregidor de León, y a Día Sánchez de Quesada, pesquisidor, permitir la entrada en dicha ciudad al arcediano de Valdemeriel, vicario de San Isidoro, a Pedro de Castellanos (a quien se le habían confiscado los bienes), a Juan Macías, y a Benito Valenciano, canónigos y beneficiados de la catedral, y a Juan Rascón, clérigo de San Martin de la villa de Escalona, diócesis de Toledo, a Blas y Pedro de Ordax, y a Juan de Candamio, canónigos de la Orden de San Agustín, que fueron acusados de la muerte del alguacil de León, Valduerna, y de otros escándalos, por lo cual se habían ausentado de la ciudad e ido a la Corte. 
Son abundantes las noticias que tenemos sobre su exceso de celo, que queda ejemplificado en sus drásticas actuaciones. Podemos destacar en este sentido sendas acciones en Segovia y en varias localidades de la Trasmiera donde apresó a numerosas mujeres acusándolas de ser mancebas de los clérigos. Su iniciativa procedía de la orden de los Reyes Católicos de imponer el celibato clerical. Amparándose en ello algunos corregidores fueron especialmente tajantes ya que les proporcionaba excelentes ocasiones de cobrar multas $^{35}$. Es el caso de Día Sánchez de Quesada, quien, intentando ejecutar las órdenes vigentes al pie de la letra, en 1487 efectuó en Segovia una serie de redadas nocturnas, saltando las vallas y rompiendo las puertas de rectorías y hogares, encarcelando a toda mujer que se encontrara dentro e que con miedos e temores que les ponía les haçia confesar ser mançebas de los clérigos, e por ello les llebaban muchas cuantías de marauedís ${ }^{36}$. Durante varios años el deán y el cabildo protestaron junto a numerosos clérigos de menor categoría alegando que no merecían un trato tan vil. Algo similar se produjo en la merindad de la Trasmiera, donde en 1489 apresó a una veintena de vecinas encarcelándolas y embargándoles los bienes, cuando no tenía suficientes argumentos para acusarlas ${ }^{37}$.

Asimismo, debido a su arbitrariedad, durante su corregimiento en las Cuatro Villas, en 1488 los Reyes Católicos ordenaron a Día Sánchez de Quesada y a su lugarteniente que se inhibieran en el conocimiento de la causa abierta por Pedro Calderón y Gonzalo de Solórzano contra Juan de Escalante y sus consortes, ya que se había decantado en defensa de los intereses de estos últimos y, por lo tanto de su bando-linaje ${ }^{38}$, desterrando a numerosos componentes del contrario ${ }^{39}$. Fue bastante polémica su actuación en este destino, donde además se le acusó de interferir en el concejo al haber sustituido al merino por uno nombrado por é $1^{40}$, de haberse quedado con los derechos del preboste ${ }^{41}$, e incluso de haberlo despojarlo de su oficio ${ }^{42}$. En medio de este conflicto, una vecina, Juana Gutiérrez Calleja, vecina de

${ }^{35}$ Lunenfeld 1989, pp. 128-129.

36 1494, abril, 7. AGS, RGS, 149404,401; 1494, mayo, 20. AGS, RGS, 149405,362; 1494, mayo, 28. AGS, RGS, 149405,361 .

${ }^{37} 1489$, diciembre, 23, Burgos. AGS, RGS, 148912,206.

${ }_{38}$ 1488, julio, 12, Burgos. AGS, RGS, 148807, 78. Solórzano 1999, docs. 37 y 38.

${ }^{39}$ AGS, RGS, 149212,196; 149410,273; 149005,359.

${ }^{40} \mathrm{El}$ merino era un funcionario nombrado por el concejo, que bajo la autoridad de los alcaldes, ejecutaba las sentencias dictadas por ellos y se encargaba de la cárcel. Solórzano 2002, p. 293. 1489, febrero, 4. Valladolid. AGS, RGS, 148902, 184.

${ }^{41} 1488$, noviembre, 8 . Valladolid. AGS, RGS, $148811,270$.

${ }^{42} 1489$, enero?, 17. Valladolid. Los Reyes ordenan que se restituyese a García Oreña en el oficio de preboste de San Vicente de la Barquera, después de que Día Sánchez de Quesada le despojara de este oficio. AGS, RGS, 148902, 309. 
Santander, le acusó de haber matado injustamente a su marido, Francisco Darze $^{43}$.

También son numerosas las denuncias de parcialidad en las sentencias, de abusos de poder y de injerencia en los concejos, por lo que en varias ocasiones intervinieron jueces pesquisidores para investigar las quejas presentadas en la corte contra Día Sánchez de Quesada. Es el caso de los vecinos de Segovia, que denunciaron arbitrariedades y agravios del corregidor en 1487, que obligó a intervenir a un juez pesquisidor de nombre Lope Ochoa de Avellaneda para que hiciera cierta averiguación sobre los oficiales del corregidor. Según se dice, cuando éste acabó la pesquisa no quiso entregar las varas de justicia al corregidor y las puso en poder del regimiento, que tardó bastante tiempo en darlas a Día Sánchez de Quesada ${ }^{44}$. Por otro lado, en 1500 los tundidores de Segovia se quejaban de su parcialidad y que se mostraba contra ellos muy odioso y sospechoso y favorable a las partes que los acusan, por lo que pedían que en los juicios contra ellos lo acompañaran los regidores ${ }^{45}$.

Sus actuaciones explican que en varias ocasiones las ciudades se negaran a acogerlo cuando se le prorrogó el cargo. Es el caso de las Cuatro Villas, donde lo rechazaron especialmente los vecinos de Castro Urdiales, inducidos por Gonzalo de Solórzano, vecino de Santander y que había sido condenado por Día Sánchez de Quesada, como hemos visto ${ }^{46}$. Tampoco fue bien recibida la prórroga de su corregimiento en Segovia ${ }^{47}$ y Zamora ${ }^{48}$. Asimismo, está justificado el recelo que contra él mostraron algunos corregidores y miembros de los concejos en los que estaba destinado. De hecho, Diego de Mendoza, corregidor de Salamanca se negó a que Día Sánchez de Quesada, su sucesor en el cargo, le hiciera juicio de residencia ya que previamente a su nombramiento había ido a Salamanca y le había investigado, por lo que pensaba que podría utilizar esa información contra él, lo que le llevó a decir que le era odioso e sos-

${ }_{43}^{4}$ 1489, enero, 22.Valladolid. AGS RGS,148901,391

${ }^{44}$ Asenjo 1986, p. 528.

${ }^{45}$ 1500, julio, 6. Valladolid. AGS, RGS, 150007, 2599, f. 101

46 1489, mayo, 28. Jaén. AGS, RGS, 148905,247 y 1489, julio, 7. Jaén. AGS, RGS, 148907,310. Son sendas sobrecartas en las que se ordena la acogida de Día Sánchez como corregidor de las Cuatro Villas y la Trasmiera tras la negativa de la villa de Castro Urdiales de recibirlo tras la prórroga de su mandato.

${ }^{47} 1488$, enero, 31. Zaragoza. Orden de los reyes Católicos a Segovia para que se reciban como corregidor a Día Sánchez de Quesada, pese a que Segovia había pedido que no lo mandasen más como corregidor "por algunas razones". AGS, RGS, 148801,299.

${ }^{48}$ 1507, junio, 7. Magaz. La reina doña Juana ordena al concejo de Zamora que reciba como corregidor a Día Sánchez de Quesada, después de su negativa a aceptarlo. AGS, RGS, 150706-146. 
pechoso e juró que la dicha sospecha non la ponía maliçiosamente ${ }^{49}$. Posiblemente, la razón de que Día Sánchez de Quesada lo investigara fuera porque los monarcas lo nombraran también pesquisidor para indagar sobre este corregidor, lo que podría haber provocado desavenencias entre ambos y la lógica animadversión de Diego de Mendoza. Otro ejemplo es la reprobación de Diego del Río, regidor de Segovia, que se quejaba de que los alcaldes y oficiales del corregidor tenían gran odio y enemistad contra él y su familia por lo que los recusaba ${ }^{50}$.

Como delegado real, el corregidor debía de ejecutar las sentencias dadas por las instancias superiores. Tenemos un curioso ejemplo del desempeño de esta función que se produjo mientras era corregidor en Salamanca, cuando se le encomendó la orden de exclaustrar a Beatriz Guiera, beata vecina de Ávila. Ésta había ingresado en el monasterio de la Encarnación de esa ciudad obligada por su padre, Pedro Suárez, después de que éste se casara por segunda vez, tuviera otro hijo, la maltratara continuamente y le exigiera que renunciara a la herencia de su madre. En ese monasterio profesaba también una hermana de su madrastra que le daba peor vida. Por ello Beatriz abandonó la institución para que posteriormente su tío y otros parientes la llevaran al monasterio de las Dueñas de Alba de Tormes. Pedro Suárez denunció a los parientes temiendo que le reclamaran la herencia, por lo que actuó el juez de residencia de Ávila. Finalmente los reyes encargaron a Día Sánchez de Quesada que la sacara el monasterio para llevarla a un lugar honesto y que mandara al juez que no actuara hasta que no se averiguara qué había ocurrido ${ }^{51}$.

\section{Los COlaboradores de Día SÁNCHEZ de QUESADA}

El corregidor contaba con un conjunto de colaboradores, tenientes o lugartenientes, que le ayudaban a realizar sus tareas y en los que en ocasiones delegaba. Estos subordinados debían ser forzosamente vecinos de otras poblaciones, a fin de evitar que los intereses creados o lazos familiares pudieran interferir en el cumplimiento de su deber, y tampoco podían reclutarse entre sus parientes. Así pues, y dado que Día Sánchez de Quesada no tenía formación como letrado, necesitaba un técnico en derecho que le auxiliara en la administración de la justicia (al menos un alcalde), además de otros colaboradores, como un brazo ejecutor que materializara en la práctica sus órdenes (un algua-

\footnotetext{
49 1494, octubre, 15. Madrid. AGS, RGS, 149410, 459. Ante ello, los reyes enviaron a Gonzalo Gómez de Villasandino, miembro del Consejo Real, para que hiciera el juicio de residencia a Diego de Mendoza.

50 1487, agosto, 29, Burgos. AGS, RGS, 148708,236.

${ }^{51}$ 1495, enero, 26, Madrid. AGS, RGS, 149501,136.
} 
cil), y otros lugartenientes que lo reemplazara en caso de tener que ausentarse. No siempre se cumplieron estas premisas, y de hecho, el concejo de Trujillo se quejó por el nombramiento de Juan Velázquez como alcalde, cuando era vecino de esa ciudad y además no era letrado ${ }^{52}$. Por otro lado, conocemos el nombre de algunos de sus colaboradores, destacando la repetición entre éstos de los apellidos Navarrete y Cabrera, de origen baezano ${ }^{53}$. En relación a los primeros sabemos que varios miembros de esta familia estaban muy vinculados al linaje de los Quesada. Así, tenemos noticias de un tal Juan de Navarrete, como oficial de la justicia del corregidor en Alcaraz ${ }^{54}$, teniendo también este nombre (no sabemos si es la misma persona) el criado que acompañaba a su hijo Pedro Díaz de Quesada cuando asesinaron al canónigo de Jaén Francisco de Reolid ${ }^{55}$. También figuran algunos parientes, como es el caso de Diego de Quesada, que fue su teniente en Segovia ${ }^{56}$.

La actitud de sus subalternos fue muy parecida a la de Día Sánchez de Quesada, por lo que tuvieron también problemas en los concejos en los que ejercieron, conservándose numerosas quejas contra su labor en las que se les acusaba de parcialidad, enemistad u odio, como la que el regidor de Segovia, Diego del Río elevó a la corte recusándolos por tal razón ${ }^{57}$. También fueron denunciados por haber impuesto multas y requisas improcedentemente, caso de Segovia, donde los reyes ordenaron en 1488 a Día Sánchez de Quesada que devolviera las cantidades que sus oficiales habían cobrado a una serie de vecinos injustamente ${ }^{58}$. Podemos destacar también la actuación de Ponce de Cabrera, uno de sus oficiales en Segovia, quien, enviado a Cuéllar para investigar si tras la expulsión los judíos habían sacado moneda y cosas vedadas y habían dejado allí deudas, apresó a dos conversos, los llevó a Segovia y les embargó sus bienes ${ }^{59}$.

\footnotetext{
${ }_{52}$ 1498, julio 22, Valladolid. AGS, RGS, 149807, 160.

${ }^{53}$ Fueron oficiales suyos en Alcaraz en 1490: Gonzalo Jiménez de Lara, Juan Navarrete, Francisco Navarrete (AGS, RGS, 149305, 179) y Rodrigo de Cabrera, su teniente, vecino de Baeza. (AGS, RGS, 149312,110); en las Cuatro Villas tuvo como ayudante a Juan Sánchez Navarrete (ayudante, AGS, RGS, 148912,206), al bachiller Francisco de Madrigal, como teniente (AGS, RGS, 148807,78), y como alcaldes a Juan Sánchez de Navarrete, Pedro Sánchez de Marrón y Vedoya (AGS, RGS,149001,169); en Segovia en 1489 tenía como oficiales a Fernando de Requena y Ponce de Cabrera, y su teniente era Diego de Quesada (AGS, RGS, 148801,155.

${ }^{54}$ AGS, RGS, 149305,179

${ }^{55}$ AGS, RGS, 149911, 177 y 178.

${ }^{56}$ 1488, enero, 20, Zaragoza. AGS, RGS, 148801,155

57 1487, agosto, 29, Burgos. AGS, RGS, 148708, 236.

${ }^{58}$ 1488, enero, 20, Zaragoza. AGS, RGS, 148801,155.

${ }^{59}$ 1493, junio, 25, Barcelona. AGS, RGS, 149306,135.
} 


\section{LA PRESENCIA DEL CORREGIDOR EN LOS CONCEJOS (ABSENTISMO Y SALARIO)}

El corregidor se hallaba a la cabeza del gobierno municipal, por lo que era el encargado de presidir el cabildo municipal. Sin embargo existía un absentismo bastante generalizado del que Día Sánchez de Quesada no fue ajeno, y en su ausencia esta función fue desempeñada por su lugarteniente o algunos de sus alcaldes. En este sentido, sabemos que en Trujillo entre los años 1498-1499 faltó a numerosos ayuntamientos. Así, mientras el primer año estuvo presente en el 73'6\%, sin embargo en 1499 la cifra se redujo a un $69^{\prime} 65 \%$ del total. En el primer año hubo dos ausencias continuadas entre el 29 de marzo y el 25 de mayo y del 24 de septiembre al 22 de octubre, mientras que en el 1499 la mayor parte de las ausencias se concentran entre el 9 de septiembre y 29 de noviembre ${ }^{60}$. A veces éstas podían estar motivadas por el cumplimiento de otras obligaciones, como la inspección de los términos o acudir a la corte. Sin embargo, en el caso de Día Sánchez de Quesada, nos atrevemos a pensar que la segunda de las ausencias, la que se produjo entre septiembre y noviembre de 1499, pudo estar motivada por una cuestión tan personal como solucionar los problemas de su primogénito, Pedro Díaz de Quesada. De hecho, sabemos que en agosto de 1499 fue asesinado a puñaladas del canónigo de Jaén Francisco Reolid ${ }^{61}$. El 27 de ese mes fue nombrado el bachiller Fernando Gil Mogollón como pesquisidor para investigar el caso ${ }^{62}$, quien en noviembre resolvió que fueron Pedro Díaz de Quesada y su criado Juan de Navarrete los que cometieron el delito, poniéndoles un plazo para que se presentaran en la cárcel. Sin embargo no comparecieron, por lo que se les acusó de rebeldes y se inició el procedimiento para que dictaminar sentencia ${ }^{63}$. La coincidencia de todo este proceso con la ausencia del corregidor de Trujillo es bastante significativa, y es muy posible que se trasladara a Baeza a ayudar a su hijo ${ }^{64}$.

El cargo de corregidor suponía la percepción de un salario bastante importante que pagaban las localidades de destino, estableciendo cada una

${ }^{60}$ Sánchez 1993, p. 150.

${ }^{61}$ 1499, noviembre, 3, Granada. AGS, RGS, 149911, 178.

${ }^{62}$ 1499, agosto, 27, Granada. AGS, RGS, 149908, 149. Nombramiento como pesquisidor de Fernando Gil Reolid por un mes para investigar la muerte de Francisco Reolid. 1499, septiembre, 19. Granada. AGS, RGS, 149909, 306. Prórroga de seis días más para continuar con la pesquisa.

${ }_{63}^{63}$ 1499, noviembre, 13, Granada. AGS, RGS, 149911, 177.

${ }^{64}$ Desconocemos cuál fue el resultado de este proceso y si resultó culpable cuál fue la pena que se le impuso, aunque es muy posible que se le condenara al destierro. $C f$. Carmona Ruiz 2015. 
el sistema para recaudar las cantidades que éste percibiría, suponiendo a veces un importante desembolso para los concejos. El sueldo de un corregidor variaba de un concejo a otro, con una media de unos 75.000 maravedís anuales ${ }^{65}$, un salario bastante elevado que se podía complementar con ingresos suplementarios procedentes de multas, comisiones, confiscaciones, o primas, además de actuaciones ilegales que le permitían enriquecerse notablemente. Día Sánchez de Quesada habitualmente fue destinado a concejos donde el salario estaba muy por encima de la media. Así, en las Cuatro Villas rondaba los 150.000 maravedís, mientras que en Madrid 73.000 maravedís $^{66}$, en Trujillo era de 150.000 maravedís $^{67}$, en Segovia entre 100.000 y 200.000 maravedís $^{68}$ $\mathrm{y}$, como veremos, si se hubiera hecho efectivo el salario que pedía, en Zamora habría cobrado alrededor de 180.000 maravedís.

De hecho, Día de Quesada se quejó en varias ocasiones por no recibir el sueldo que le correspondía, al ser una pesada carga para los concejos. Así, en 1506 Día Sánchez de Quesada protestaba porque habitualmente los corregidores cobraban en Zamora 500 maravedís diarios, y que a él el concejo zamorano le quería pagar 400 maravedís ${ }^{69}$. El desembolso que debía hacer el concejo de Zamora era bastante notable, y si nos guiamos por las palabras de Día Sánchez de Quesada, su salario debía haber ascendido a 182.500 maravedís anuales, muy por encima de la media habitual, que, como hemos dicho era de unos 73.000 maravedís al año. De hecho, la ciudad de Zamora tuvo bastantes problemas para pagar a los corregidores y para este fin, fueron alternando el uso de los propios con los repartimientos entre los vecinos de la ciudad. Por ello en 1500 los Reyes Católicos ordenaron que el pago se hiciera únicamente por repartimiento. Sin embargo, en 1505 Día Sánchez de Quesada usó los propios de la ciudad para su salario, por lo que, ante la queja de la ciudad, la reina doña Juana ordenó que se le pagara mediante un repartimiento ${ }^{70}$. De hecho, el mismo mes de octubre se realizó un repartimiento en el que se recaudaron 93.268 maravedís, destinándose 61.000 maravedís a pagar el salario de Día Sánchez de Quesada, y el resto a financiar las exequias de la reina Isabel ${ }^{71}$.

Considerando el elevado salario del corregidor, y los beneficios extras que podía alcanzar, y que en el caso de Día Sánchez de Quesada sabemos que obtuvo debido a las constantes quejas que particulares presentaron a la

\footnotetext{
${ }^{65}$ Lunenfeld 1989, pp. 94-95.

${ }^{66}$ Lunenfeld 1989, p. 94.

${ }^{67}$ Sánchez 1993, p. 154

${ }^{68}$ Lunenfeld 1989, p. 95; Asenjo 1984, p. 960.

69 1506, agosto, 30, Tudela. AGS, RGS, 1506-08-866

${ }^{70} 1505$, octubre, 10, Segovia. AGS, RGS, 1505-10-360

${ }^{71}$ Ladero 2000, p. 130
} 
corte por el cobro abusivo de multas, nos puede sorprender que no consiguiera incrementar la hacienda familiar. Así, su mujer, Doña Leonor de Acuña, nos muestra algunos indicios de la falta de numerario en su testamento y en el pleito que en 1529 se produjo sobre la propiedad de Nínchez y Chozas, los testigos indican que a la muerte de Día Sánchez de Quesada éste sólo dejó los bienes del mayorazgo ${ }^{72}$.

Una de las razones que da para esa situación es que gastaron en su primogénito, Pedro Díaz de Quesada, grandes cantidades de dinero en el estudio, pleitos y necesidades que tuvo después de casado, por lo que le dieron para su sustento y matrimonio rentas procedentes del señorío de Santo Tomé de más de 12 años. Ya hemos hecho referencia al pleito que mantuvo por el asesinato de un arcediano jienense, y es muy probable que su padre se gastara importantes cantidades de dinero en su defensa. Pero además, doña Leonor en su testamento no dejó nada a sus nietos, hijos de Pedro Díaz de Quesada, al considerar que su padre había recibido demasiado. Por otro lado, cuando su hija Isabel se casó con el regidor baezano Carlos de Biedma, Día Sánchez de Quesada y Leonor de Acuña establecieron una dote de 250.000 maravedís, que no pudieron hacer efectiva por su falta de numerario, por lo que le entregaron en prenda el cortijo de Chozas. Al ser parte de sus bienes dotales, en 1515 doña Leonor vendió esta heredad a Diego de Deza, arzobispo de Sevilla por 450.000 maravedís, pagándole con ello a su hija la cantidad que se le debía ${ }^{73}$.

\section{DENUNCIAS PRESENTADAS CONTRA LA GESTIÓN DE DÍA SÁNCHEZ DE QUESADA. LOS JUICIOS DE RESIDENCIA}

En la documentación conservada sobre la actuación del corregidor Día Sánchez de Quesada destaca la abundancia de las quejas de particulares presentadas a la corte denunciando algunos abusos por los que obtenía pingües beneficios. Hemos visto las redadas y embargos que hizo a numerosas mujeres en Segovia y Trasmiera, así como su intervención en la lucha de bandos en las Cuatro Villas, que aprovechó para confiscar los bienes de los contendientes, pero también hay abundantes demandas por toma indebida de bienes en el resto de los corregimientos a los que fue destinado.

\footnotetext{
${ }^{72}$ ARGr 888/005

${ }^{73}$ SNAHN, Baena, C. 102, D. 23. La venta se produjo en 1515, junio 22. Baeza. Diego de Deza tomó posesión del cortijo y posteriormente se lo donó a su sobrina Inés de Tavera que lo aportó como dote para su casamiento con Día Sánchez de Quesada IV, señor de Garcíez. SNAHN, Baena, C. 68, D. 15-22.
} 
Entre todas las arbitrariedades que Día Sánchez de Quesada cometió podemos destacar la que denunciaron numerosos vecinos de la Trasmiera en 1490 debido a que un tal Juan de Barahona, vecino de Villanueva de Laredo, había adquirido de los reyes la merced de cobrar las sanciones por no haber cubierto el servicio de peones para la guerra entre los años 1487 y 1489. Éste a su vez había vendido ese derecho a Día Sánchez de Quesada por 30.000 maravedís, quien, con la intención de recaudar las multas y recuperar lo invertido, actuó de una manera bastante violenta, confiscando bienes de numerosos vecinos, incluso de algunos que estaban en la guerra, que habían muerto en la misma, o que habían servido en algún momento en ella, azotando a unos vecinos, rompiendo las puertas para llevarse sus bienes y apresando a otros ${ }^{74}$, habiendo conseguido durante esos tres años entre 500.000 y 700.000 maravedís. Ante la respuesta violenta del corregidor, los Reyes Católicos nombraron juez pesquisidor a Machín de Vildosola ${ }^{75}$.

También su sucesor como corregidor de Alcaraz, Pedro Ortiz, denunció en el juicio de residencia la actitud de Día Sánchez de Quesada, acusándolo de haberse llevado importantes cantidades de dinero por su actividad como capitán de la ciudad en el cerco de Granada y por multas injustificadas ${ }^{76}$. Además, había intentado conseguir que el gobierno le concediera una cuenta para gastos de vestuario ${ }^{77}$. Del mismo modo, en 1488 los reyes ordenaron al corregidor y sus oficiales que devolvieran a varios vecinos de Segovia las cantidades que le habían tomado en concepto de multas ${ }^{78}$.

Buena parte de la información que tenemos sobre estas denuncias procede de la documentación aportada para los juicios de residencia a los que se sometió. La finalidad de estas inspecciones judiciales era garantizar la conducta correcta de los corregidores al terminar su ejercicio. Con estos juicios se pretendía que los súbditos agraviados por la actuación de los corregidores y sus colaboradores obtuviesen la satisfacción de sus legítimos intereses después de que cesaran en el cargo, aunque también permitía que los reyes pudieran controlar a sus delegados, medir su lealtad y su grado de identificación con las leyes que se les manda aplicar ${ }^{79}$. Como otros corregidores, Día Sánchez de Quesada también fue objeto de control, aunque no siempre mediante el juicio de residencia. Así, sin haber prestado juicio de residencia en Segovia, en enero de 1488 fue nom-

\footnotetext{
${ }^{74}$ 1490, enero, 23, Burgos. AGS, RGS, 149001,169.

75 1490, febrero, 24, Burgos. AGS, RGS, 149002,272.

${ }^{76}$ 1493, mayo, 24, Barcelona. AGS, RGS, 149305,179.

${ }^{77}$ Lunenfeld 1989, p. 112.

${ }^{78}$ 1488, enero, 20, Zaragoza. AGS, RGS, 148801,155.

${ }^{79}$ González Alonso 2000, pp. 261 y ss.
} 
brado corregidor de las Cuatro Villas ${ }^{80}$, lo que provocó las quejas de los segovianos. Ante ello, los reyes ordenaron al concejo de Segovia que no molestaran al corregidor, alegando que anteriormente había sido sometido a pesquisa y no se le había considerado culpable ${ }^{81}$. Tampoco hizo residencia en Alcaraz, donde estuvo entre 1490 y 1492, aunque su sucesor, Pedro Ortiz, realizó una pesquisa sobre su actuación. Finalmente se ordenó al licenciado Francisco Muñoz, juez encargado de realizar el juicio de residencia a Pedro Ortiz en 1493, que recibiera también la residencia pendiente de Día Sánchez de Quesada ${ }^{82}$.

Día Sánchez de Quesada ejerció como corregidor hasta poco antes de su fallecimiento en 1507. Así, el 23 de julio de ese año se ordenaba que éste hiciera residencia ante Gonzalo Martínez de Villavela ${ }^{83}$, y poco después, el 25 de octubre, la reina doña Juana nombraba como regidor de Baeza a Pedro Fernández de Nicuesa en sustitución de Día Sánchez de Quesada, ya que éste había fallecido ${ }^{84}$. Su defunción debió de ser inesperada, lo que puede explicar que no hubiera testado ${ }^{85}$.

\section{CONCLUSIONES}

A través de estas páginas se ha intentado exponer la actuación de Día Sánchez de Quesada, uno de los corregidores que más extensa vida laboral tuvo al servicio de los Reyes Católicos, que sólo puede ser explicable por la especial confianza que depositaron en él los monarcas. Las continuas prórrogas en su cargo y la elección de los destinos, generalmente lugares donde la conflictividad local era bastante patente, es muestra de ello. Sin embargo, y pese a que su función principal era la de dirigir la vida política de los municipios en beneficio del poder central, no siempre consiguió ser eficaz, y de hecho, a través de estas páginas queda bastante patente su falta de capacidad para imponerse sobre las facciones que existían en los concejos a los que estuvo destinado, como tampoco consiguió impartir justicia imparcialmente sin inclinarse a favor de alguna de las parcialidades, según se puede ver en el caso de las Cuatro Villas, donde el corregidor no actuó como un poder moderador, sino que gobernó con el apoyo de una de las facciones en detrimento de los intereses de la contraria, algo que ocurría bastante a menudo ${ }^{86}$.

\footnotetext{
${ }^{80}$ AGS, RGS, $148801,287$.

${ }^{81}$ 1488, marzo, 18. AGS, RGS, 148803, 138.

${ }^{82}$ AGS, RGS, 149305,172.

${ }^{83} 1507$, julio, 23, Palencia. AGS, RGS, 1507-07-277.

${ }^{84} 1507$, octubre, 25, Burgos. AGS, RGS, 1507-10-104

${ }^{85}$ Así se manifiesta en un pleito que se produjo entre sus hijos Gil y Teresa. ARChGr 2226/006.

${ }^{86}$ Diago 2004, p. 206.
} 
Desde el principio de su actividad Día Sánchez de Quesada mostró un carácter expeditivo que no abandonó nunca a lo largo de su carrera, lo que explica la cantidad de quejas que se conservan por su actuación. Es posible que en alguna ocasión pudieron ser motivadas por el intento de los afectados de evitar unas sentencias poco favorables, pero la intervención de la corona en otros casos ordenando la devolución de lo embargado muestra que las resoluciones de Día Sánchez de Quesada no fueron todo lo ecuánimes que se debería haber esperado. Las quejas que se presentaron contra él eran todo un clásico dentro de las denuncias que habitualmente los concejos interponían contra los corregidores: abuso y arbitrariedad en el ejercicio de poder; exceso o falta de celo en sus funciones; intromisión, anulación o extorsión de los poderes locales; abuso en el cobro de las multas o impuestos y su apropiación indebida; nombramiento de subalternos locales, nepotismo... que habitualmente correspondían a una realidad manifiesta y toda una muestra de su falta de ética profesional. Hay que destacar, en cualquier caso, que pese a ello, los Reyes Católicos confiaron lo suficientemente en él como para que tuviera una larga carrera que sólo la muerte truncó.

Considerando su larga trayectoria como corregidor, resulta cuanto menos curioso que habiendo obtenido cuantiosos ingresos por el desempeño de su cargo no repercutiera favorablemente en la hacienda familiar, dejando tras su muerte tan sólo los bienes propios del mayorazgo. Es muy posible que su propio talante, o los problemas que su primogénito, Pedro Díaz de Quesada, le pudieron acarrear le supusieran un importante desembolso económico, pero también es posible que los excesos de los que se le acusaba no fueran tantos, lo que explicaría también la confianza que los monarcas depositaron en él.

\section{BIBLIOGRAFÍA CITADA}

Asenjo González, María (1984), La Extremadura castellano-oriental en el tiempo de los Reyes Católicos, Madrid, Universidad Complutense.

Asenjo González, María (1986), Segovia. La ciudad y su tierra a fines del medievo, Segovia, Diputación Provincial.

Bermúdez Aznar, Agustín (1974), El corregidor de Castilla durante la Baja Edad Media (1348-1474), Murcia, Universidad de Murcia.

Bonachía Hernando, Juan Antonio (1998-1999), Materiales para el estudio del régimen de corregidores (Burgos, 1458-1465), "Cuadernos de Historia de España" 75, pp. 135-160.

Carmona Ruiz, María Antonia (2009), La mentira como arma. Pleitos en torno a la propiedad de un mayorazgo. Nínchez y Chozas (ss. XV-XVI), "Historia. Instituciones. Documentos" 36, pp. 113 -137. 
Carmona Ruiz, María Antonia (2012), La presión real y señorial sobre el patrimonio de los concejos Andaluces en la Baja Edad Media. El caso de la Dehesa de la Torre de Don Ibáñez (Baeza) en Mundos medievales: espacios, sociedades y poder: homenaje al profesor José Ángel García de Cortázar y Ruiz de Aguirre, Santander, Ediciones de la Universidad de Cantabria, vol 2, pp. 1149-1160.

Carmona Ruiz, María Antonia (2015), Los Quesada, señores de Garcíez y Santo Tomé (Jaén) durante la dinastía Trastámara, "Espacio Tiempo y Forma" 28, pp. 159-199.

Carmona Ruiz, María Antonia (2017a), En torno al origen de los señoríos del reino de Jaén. La génesis del linaje de los Quesada, señores de Garcíez y Santo Tomé (Jaén). Siglos XIII-XIV, "Medievalismo" 27.

Carmona Ruiz, María Antonia (217b), Doña Leonor de Acuña y el linaje de los Quesada, señores de Garcíez y Santo Tomé (Jaén) en Autoridad, poder e influencia: Mujeres que hacen historia, Barcelona, Icaria, pp. 67-83.

Cózar Martínez, Fernando de (2006). Noticias y documentos para la Historia de Baeza, Granada, Universidad de Granada.

Diago Hernando, Máximo (2004), El papel de los corregidores en los conflictos políticos en las ciudades castellanas a comienzos del siglo XVI, "En la España Medieval" 27, pp. 195-223.

González Alonso, Benjamín (1970), El corregidor castellano (1348-1808), Madrid, Instituto de Estudios Administrativos.

González Alonso, Benjamín (1995), Poder regio, reforma institucional y régimen político en la Castilla de los Reyes Católicos, en El Tratado de Tordesillas y su época, Valladolid, Junta de Castilla y León, vol. I, pp. 23-48.

González Alonso, Benjamín (2000), Los procedimientos de control y exigencia de responsabilidad de los oficiales regios en el Antiguo Régimen (corona de Castilla, Siglos XIII-XVIII), "Anuario de la Facultad de Derecho de la Universidad Autónoma de Madrid" 4, pp. 249-272.

González Alonso, Benjamín (2001), Monarquía, ciudades, corregidores (Castilla 1480-1523), en Belenguer Cebriá, Ernest (coord.), De la unión de coronas al Imperio de Carlos V, Madrid, Sociedad estatal para la conmemoración de los centenarios de Felipe II y Carlos V, vol. I, pp. 281-298.

Guerrero Navarrete, Yolanda (1994-1995), La política de nombramiento de corregidores en el siglo XV: entre la estrategia regia y la oposición ciudadana, "Anales de la Universidad de Alicante" 10, pp. 99-124.

Ladero Quesada, Manuel Fernando (2000), Recibir princesas y enterrar reinas (Zamora 1501 y 1504), "Espacio, Tiempo y Forma. Serie III, Historia Medieval" 13, pp. 119-137. 
Lunenfeld, Marvin (1989), Los corregidores de Isabel la Católica, Barcelona, Labor.

Mitre Fernández, Emilio (1969), La extensión del régimen de corregidores en el reinado de Enrique III de Castilla, Valladolid, Universidad de Valladolid.

Mackay, Angus (1985), Anatomía de una revuelta urbana: Alcaraz en 1458, Albacete, Instituto de Estudios Albacetenses.

Martín Pérez, Fernando (2014), Común y protesta social en San Vicente de la Barquera a finales de la Edad Media, en Los grupos populares en la ciudad medieval europea, Logroño, Instituto de Estudios Riojanos, pp. 345-371.

Parejo Delgado, María Josefa (1988), Baeza y Úbeda en la Baja Edad Media, Granada, Don Quijote.

Porras Arboledas, Pedro A. (1993), Historia del señorío y villa de Jabalquinto, Jaén, Diputación de Jaén.

Pretel Marín, Aurelio (1978), Una ciudad castellana en los siglos XIV y XV. (Alcaraz 1300-1475), Albacete, Instituto de Estudios Albacetenses.

Pretel Marín, Aurelio (1979), La integración de un municipio medieval en el estado autoritario de los Reyes Católicos (La ciudad de Alcaraz, 1475-1525), Albacete, Instituto de Estudios Albacetenses.

Sánchez Rubio, María de los Ángeles (1993), El Concejo de Trujillo y su alfoz en el tránsito de la Edad Media a la Edad Moderna. Badajoz, Universidad de Extremadura.

Solórzano Telechea, Jesús Ángel (1999), Colección documental de la villa medieval de Santander en el Archivo General de Simancas. (13261498), Santander, Concejalía de Cultura.

Solórzano Telechea, Jesús Ángel (2002), Santander en la Edad Media. Patrimonio, parentesco y poder, Santander, Universidad de Cantabria.

Solórzano Telechea, Jesús Ángel (2005), Del conflicto al delito: la violencia en la sociedad urbana de Cantabria durante la Baja Edad Media en II Encuentro de Historia de Cantabria, Santander, Universidad de Cantabria, pp. 339-369.

Suárez Fernández, Luis (ed.) (1964), Documentos acerca de la expulsión de los judíos. Valladolid, Consejo Superior de Investigaciones Científicas Patronato Menéndez Pelayo.

Fecha de recepción del artículo: febrero 2015

Fecha de aceptación y versión final: septiembre 2015 